\title{
Development of the module software for control technological processes of the gravitationally- pneumatic grain cleaner
}

\author{
Stanislav Gerasimenko ${ }^{1}$, Artak Adamyan ${ }^{1,{ }^{*}}$, Maksim Moskovsky ${ }^{1}$ and Bui Quang Minh ${ }^{2}$ \\ ${ }^{1}$ Federal scientific Agroengineering center VIM, 109428, $1^{\text {st }}$ Institutsky proezd, Moscow, Russia \\ ${ }^{2}$ Hanoi University of Agriculture, Hanoi, Vietnam.
}

\begin{abstract}
Increasing in the volumes of processed cereals crops and leguminous crops products is the main reason for the decrease in the productivity of the separation process of the impurities and the quality of the final product. In this regard, the automation of technological processes is a topical aim. This article presented the process of creating a software module to control and manage the main parameters of agricultural processes. On the basis of this developed software, an experimental model was designed and tests were conducted.
\end{abstract}

\section{Introduction}

Due to the increased volume of processed grain products, the productivity of the process of separation of impurities (bulk separation process) and the quality of the final product (seed calibration) decreases. In addition, the existing grain cleaning lines use manual adjustment, which results in lower productivity due to downtime, grain loss during separation and main fraction calibration. There is also increased wear and tear on existing machines, including foreign ones.

The tasks of automating technological processes are particularly topical at the backdrop of these problems due to the using of software modules and the development of algorithms for automatic control programs [1].

The aim of the research is creation the software module to control and operate the main parameters of the pneumatic separation process and gravitational calibration process of cereals and legumes in the gravitational-pneumatic cleaner.

\section{Materials and methods}

The signals sequence has been developed in the CODESYS industrial automation program complex. The basis of this complex is the application development environment for programmable logic controllers (PLCs) [2].

Five software programming language defined by IEC 61131-3 standard are available for programming. In this case, the program has been developed on the CFC language, which

\footnotetext{
${ }^{*}$ Corresponding author: garikbegun@yandex.ru
} 
language is addition to the FBD (function blocks) language, the basis of FBD (function blocks) language is the random arrangement of blocks and arrangement of the order in its executed [3].

The source of the signal sequence is the Raspberry Pi 3 microcomputer. The connection of the necessary servomotor outputs to the microcomputer is carried out via a logic signal level converter (Fig. 1.), since the logical unit of Raspberry Pi 3 is $3.3 \mathrm{~V}[4,5]$.

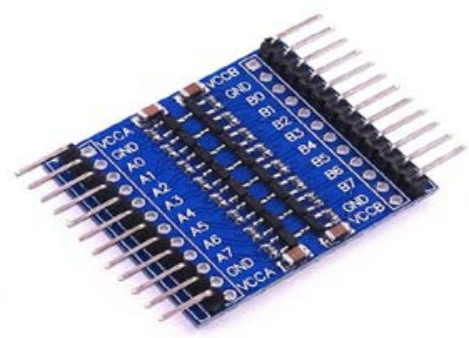

Fig. 1. Signal level converter

The implementation of an automated system as a software module will improve the quality of post-harvest grain and seed processing by using modern drives [6], based on stepper engines, as well as the use of an air flow sensor built into the precision air channel of the grain cleaning machine $[7,8]$.

\section{Results and discussions}

The principle of automating machine operation is as follows. The laser module sends a signal to the photodiode, which indicates that there are no obstacles between the two objects, so the hopper is not full. If the photodiode stops receiving the signal from the laser module, it means that the bunker is full, as the material overlaps with the signal emitted by the laser. Then a start-up signal is received from the Raspberry Pi 3 microcomputer to the stepper motor, which serves to close the air channel hopper flap. The system works the same way on the gravity channel.

Table 1 shows the ratio of the servomotor inputs/outputs to Raspberry Pi 3.

Table 1. Correlation of inputs/outputs

\begin{tabular}{|c|c|}
\hline Servomotor outputs & Contacts Raspberry Pi 3 \\
\hline PMW & Pin 2 - 3.3V Power \\
\hline Ground & Pin 6 - GND \\
\hline Vcc & GPIO18 \\
\hline
\end{tabular}

It is necessary to send needful pulse sequence to the signal contact of the engine for making capability of the control of the servomotor. The scheme of the connection of the servomotor contacts to the control device is shown in Figure 2(a). 


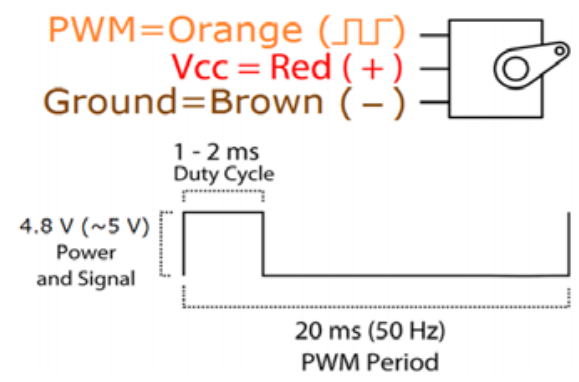

a)

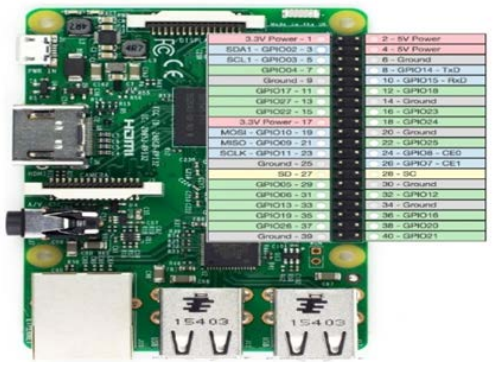

b)

a - the way of the servomotor connection;

b - GPIO outputs on Raspberry Pi 3.

Fig. 2. Contacts connection scheme

Also, air flow speed sensor was installed in the air channel system, which measures the speed changes in the cleaner's air channel. If the output signal is equal or greater than the set standard, Raspberry Pi 3 sends a signal to the stepper engine to stop the damper on the bunker. Consequently, the material supply is stopped, which signals that the filters are full of dust, the cleaning electric motor must stop and the filter must be replaced.

A view of the final step engine rotation control program (RCP) is shown in the Figure 3.

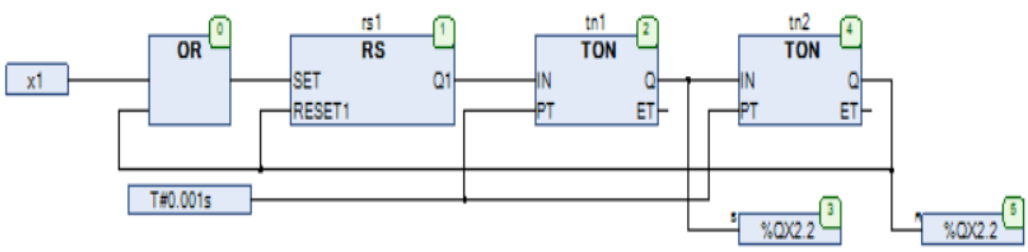

Fig. 3. Control program RCP

Also it is need to go to the GPIO's configuration tab and switch the connected outputs to the Output state (GPIO17, GPIO18, GPIO22, GPIO23) as shown in the Figure. 4.

In the future, the rotation of the servomotor will be controlled by a laser sensor.

The laser has 2 wires: power and ground. The photo sensor has three wires: power, ground and signal. The power supply, ground of the laser and the photo sensor are connected to the common power and ground buses, while the signal wire of the photo sensor, through a pulse converter, is connected to the microcomputer GPIO18 input. The control program will takes the following form (Fig. 4):
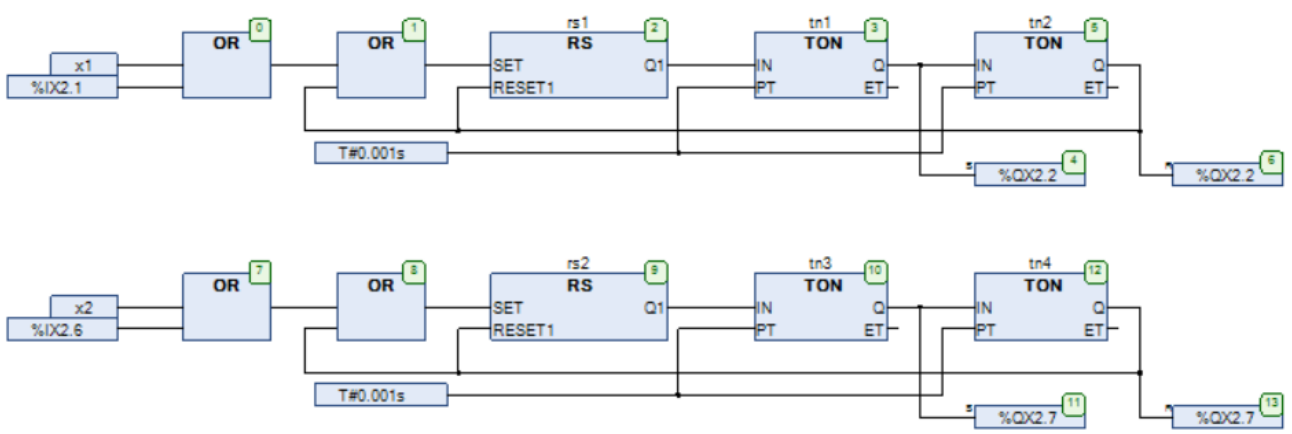

Fig. 4. Laser sensor control program for the stepper engine 
The control signal for the servomotor now comes directly from the photodiode. This makes possible to automatically start and stop the servomotors mounted on the damper, which controls the start or stop of their grain feed of tanker $[9,10]$.

In order to be able to control the air flow rate in the pneumatic channel, we connect an analogue fan (simulating the operation of fans on a grain cleaning machine) to a control device on the layout. Its control is similar to that of a servomotor.

Special bags are installed on the machine in each channel for the control the filling of bags with unused waste, which during the grain cleaning process filters the air passing through them and collects dust fragments. During the machine's operation, these bags are clogged and there is a need for immediate cleaning.

Below in the Figure 5 presents the part of the program that will control the filling of bags with unused waste.

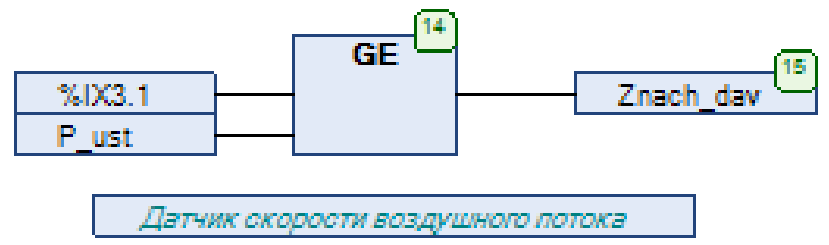

Fig. 5. Connection of air flow velocity sensor

The idea of installing a relative pressure sensor was suggested to detect the fullness of bags of dust in time. If the pressure rises above the preset value, which is set in advance, the system will signal the operator to clean the bags. At the same time, a signal will automatically be given to the servodrives that will stop the grain being fed into the channels.

It is shows the layout of the software module on the Figure 6. The final description of the logical sequential operations of the software module is as follows: laser emitters $(5,9)$ are installed in the gravity-pneumatic cleaner's tanker and feed a signal to the photodiodes $(4,8)$, which signals that there are no obstacles between the two objects, hence the tanker is not full. If the photodiode stops receiving the signal from the laser module, this means that the tanker is full, as the source material overlaps with the emitted signal. In this case, a signal is received from the Raspberry Pi 3 (1) microcomputer to the servo drive $(6,7)$ to start the stepper engine, which is used to close the tanker valve on the pneumatic channel. The system works the same way on the gravity channel. The system also has an air flow velocity sensor (3), which controls the pressure in the pneumatic channel created by the electric engine fan (2). If the output signal is equal to or higher than the set standard, the Raspberry Pi 3 microcomputer sends a signal to the stepper motor to close the valve on the hopper, therefore, the grain supply is stopped and the controller signals (by sound and/or light signal) on the control device that the dust in the filters is full - filter cleaning requirement $[11,12]$. 


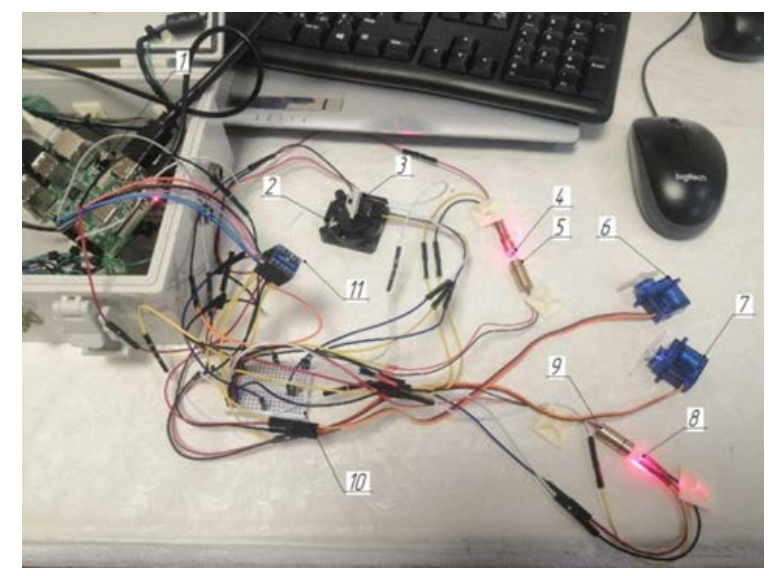

1 - microcomputer Raspberry Pi 3, 2 - electric fan, 3 - relative air pressure sensor, 4.8 - photodiodes, 5.9 - laser emitters, 6.7 - servo drive, 10 - model board, 11 - signal converter

Fig. 6. Experimental model of the program module for control and operate of technological parameters in grain separation and leguminous crop calibration

\section{Conclusions}

Hardware was developed in the form of a created experimental model of the control software module, taking into account the principles of the gravity-pneumatic separator. The response is the launch of the control program on the experimental model and the correct operation of the actuators.

As a result of the research performed, the automated control program has the following capabilities:

- control of the grain supply system using laser sensors and servo motors;

- $\quad$ air flow speed control;

- $\quad$ alarm system for bag filling with dust, by measuring pressure in the ducts.

The research was supported by the "Fund for Assistance to Innovations" under the program "U.M.N.I.K." project No. У-58497.

\section{Reference}

1. V.P. Diakonov, Matlab and Simulink: fundamentals of application (Solon-Press, 2002)

2. Raspberry Pi Foundation [Electronic resource] - access mode: https://projects.raspberrypi.org/en/projects/raspberry (accessed 05.03.2020)

3. Dev. practice - SOFTWARE development, technology and science [Electronic resource] — access mode: https://devpractice.ru/raspberry-pi-autostart-chromium (accessed 25.02.2020)

4. Control Engineering [Electronic resource] - access mode: https://controlengrussia.com/ (accessed 24.02.2020)

5. A.A. Adamyan, V.H. Al-Tibbi Stepper motor control based on a single-Board Raspberry Pi 2 computer in CODESYS V3.5 (Don State Technical University, Rostovon-don, Russia)

6. Electric drive [Electronic resource] - access mode: https://electroprivod.ru/pdf/smsd4.2rs485-pasp.pdf (accessed 04.03.2020) 
7. M.N. Moskovsky, V.G. Khamuev, S.A. Gerasimenko, Intensification of soybean seed separation processes, Electrotechnologies and electrical equipment in the agroindustrial complex, v 4(37), pp. 143-147 (2019)

8. A.S. Dorokhov, M.N. Moskovsky, V.G. Khamuev, S.A. Gerasimenko, Determination of optimal kinematic parameters of a sieve mill during separation of selection seed samples, Bulletin of the Federal state educational institution of higher professional education "V.P. Goryachkin Moscow state University", v. 6(88), pp. 10 (2018)

9. Ampercote [Electronic resource] - access mode: https://amperkot.ru/ (accessed 30.09.2020)

10. CODESYS Store [Electronic resource] — access mode: https://store.codesys.com/ (accessed 15.02.2020)

11. I.V. Petrov, Diakonov V.P., Programmable controllers. Standard languages and techniques of applied design (Moscow: SOLON press, 2004)

12. Litvinov M.A., Moskovsky M.N., Adamyan A.A., Development of a microprocessor control system for seed seeding, Federal scientific Agroengineering center VIM 